\title{
Assessment of Knowledge of Cervical Cancer and Pap Smear Screening in Makurdi Metropolis
}

\author{
Perpetua Ngosoo Chia ${ }^{1}$, Francis Kyernum Udzua ${ }^{2}$ and Jonathan Iornenge Ugese ${ }^{3}$ \\ 1. Department of Clinical Psychology, Federal Medical Centre, Makurdi, Nigeria \\ 2. Department of Psychology, Benue State University, Makurdi, Nigeria \\ 3. Department of Psychology, Nigeria Defence Academy, Kaduna, Nigeria
}

\begin{abstract}
Knowledge of cervical cancer and Pap smear screening in a sample population in Makurdi metropolis was assessed using a survey design. Five hundred and seventy-four (574) participants aged 18-60 years, who were accidentally/conveniently sampled in the town, took part in the study. Of this number, 48.3\% $(\mathrm{N}=277)$ were males, and $51.7 \%(\mathrm{~N}=297)$ were females and from diverse occupations. Data were collected using a standardized questionnaire, the knowledge of cervical cancer and Pap Smear Screening Scale (KCPS) with ten items. Results reveal that participants have limited knowledge on cervical cancer and Pap Smear Screening with $35.3 \%(\mathrm{~N}=203)$ having knowledge, while $64.7 \%(\mathrm{~N}=371)$ having limited knowledge. No statistical significant difference in the knowledge of cervical cancer and Pap Smear Screening between older and younger participants $t(553)=-1.69 ; P>0.05$, Single and Married participants $t(562)=-0.97 ; P>0.05$, low and high levels of education $t(564)=-1.83 ; P>0.05$ was found. Surprisingly, males (mean $=33.55)$ significantly had more knowledge of cervical cancer and Pap Smear Screening than females $($ mean $=32.26) t$ $(572)=2.03 ; P<0.05$ and other participants had better knowledge than health workers $t(572)=-2.43 ; P<0.05$. Enlightenment campaigns, Magazines and News papers, Television, Radio, Friends and Schools were some of the sources participants acquired knowledge of cervical cancer and Pap Smear Screening. It is obvious that knowledge of cervical cancer and Pap Smear Screening is limited among the population in Makurdi metropolis, therefore a need to intensify enlightenments and awareness campaigns targeted at all groups of people is imperative.
\end{abstract}

Key words: Assessment, knowledge, cervical cancer, Pap smear screening, Makurdi metroplis.

\section{Introduction}

Being aware, knowledgeable or educated on an issue or situation is very essential in the life of everyone since it enables individuals to take or make informed decisions on the issue at stake and follow it up with appropriate actions. This is in tandem with the popular adage which says that, "Knowledge is power and ignorance a deadly disease". With knowledge on various issues readily available to us we can conquer the world.

Health they say is wealth, which implies that if one is healthy one can achieve anything in life; but where one is unhealthy he/she may spend all his/her resources on achieving good health and may never be wealthy. Therefore, knowledge on health issues (such

Corresponding author: Perpetua Ngosoo Chia, research field: clinical psychology/psycho-oncology. as cervical cancer and pap smear screening) enables us to be aware of the said health issues, their causes, risk factors, implications and the various alternatives or pro-health behaviors we can take in order to remain healthy and avert suffering, morbidity and mortality. Therefore the interest to assess the knowledge of the population in Makurdi metropolis on cervical cancer and Pap smear screening becomes timely and imperative.

Cervical cancer is the most easily preventable cancer among all the cancers, but it remains one of the most common cancers among women worldwide with most of the deaths occurring in low to middle-income countries [1]. In Nigeria, 26 women die daily and 14,000 are diagnosed of cervical cancer yearly [2], while 9,656 deaths are recorded annually [3].

The cervix is regarded as the "Mouth of the womb"; it is that part of the uterus that opens into the vagina. 
Cervical Cancer is therefore that cancer which originates from the cervix and spreads to other internal organs. Technically, Cervical Cancer is abnormal cell growth in the cervix that is caused by infection with Human Pappilloma Virus (HPV) (a Sexually Transmitted Infection) which brings about abnormal cell changes/pre-cancerous lesions in the mucus lining of the cervix.

The female usually gets infected with the HPV in her early teens, 20's or 30's through sexual intercourse with an infected partner; and Cervical Cancer can develop 20 years or more after HPV infection. The HPV is the most common sexually transmitted infection worldwide and is said to affect an estimated $50 \%$ to $80 \%$ of sexually active women at least once in their life time $[4,5]$. There is no current cure for HPV but its consequences can be treated. While all women with Cervical Cancer have had HPV, less than $5 \%$ of women with HPV ultimately develop Cervical Cancer. HPV infection is usually asymptomatic which is the reason why it is not given attention till symptoms of advanced Cervical Cancer are observed. Campbell [6], states that $60 \%$ to $70 \%$ of cancer cases (in Nigeria) including Cervical Cancer present late in the hospitals, by which time the disease is already in its advanced stage resulting to low rates of cure and high morbidity (suffering and death).

Pap Smear Screening is a screening method that detects abnormal cells/pre cancerous lesions on the lining of the cervix which is a consequence of HPV infection. When detected, the pre-cancerous condition is treated. Pap smear screening is a simple test carried out on women where the cells of the cervix are smeared on a slide and taken to the laboratory for cytology examination. The aim of the screening is to detect early pre-cancerous lesions and treat them accordingly before they can develop into advanced and invasive cervical cancer.

Pap smear screening is one of the best tests a woman can take [7]. Among the reproductive tract malignancies, cervical cancer is the only one that is almost totally preventable by the detection through regular cytological screening and treatment of its pre-cancerous lesions. Every woman should be screened at every opportunity of contact with a health professional at first ante-natal visit, family planning clinics, STI clinics and gynecological clinics. Women who are sexually active should have an annual screening done from age 18 to 35 years; thereafter every 3 to 5 years if the result remains negative.

Empirical studies have reported poor, little or no knowledge by women and the general public on cervical cancer and pap smear screening. A comparative study of knowledge of cervical cancer and screening practice among female staff of University of Lagos and Yaba College of Technology, Yaba by Apampa [8] reveals that in University of Lagos, $23.7 \%$ of the participants had no knowledge and $55 \%$ had poor knowledge of cervical cancer and screening practices; while in Yaba College of Technology, 33.1\% had no knowledge and $53.1 \%$ had poor knowledge of cervical cancer and screening practices. Nonetheless respondents from University of Lagos where more knowledgeable with $21.3 \%$ having fair to good knowledge compared to $13.5 \%$ from respondents of Yaba College of Technology. 2000 women in Ogun state, Nigeria who were assessed in a study by Abiodun, Fatungase, Olu-Abiodun, Idowu-Ajiboye and Awosile [9], revealed that awareness of cervical cancer and screening was very low $(6.5 \%$ and $4.8 \%$ respectively) and also knowledge of the variables.

Similarly, Nwankwo, Aniebue, Aguwa, Anarado and Agunwah [10], in their study among urban and rural women in South Eastern Nigeria showed that there is very poor knowledge of cervical cancer and screening among the participants. The study of Nakalevu [11] also revealed that women studied in Fiji on knowledge of cervical cancer and Pap smear screening had poor knowledge, since $67 \%$ of the participants showed poor knowledge on the issue.

Generally, most studies in Nigeria have recorded low levels of Pap smear knowledge such as those of 
Feyi-waboso, Kamaru and Aluka, Audu, El-Nafaty, Khalil and Otubu, Oyiyi and Dike, Ayinde, Omigbodun and Ilesanmi, and Ogunbode [12-16]. For instance in the study of Ogunbode [16], in Ibadan, only $19.7 \%$ participants were aware of pap smear test, while in Maiduguri, less than $10 \%$ of the participants were aware of cytological screening. Similarly, in Orlu only $6 \%$ of the participants were aware of Pap smear $[13,14]$. Other studies in Nigeria focused on Health Care Providers and recorded higher levels of Pap smear awareness. For example, in Nnewi awareness was $87 \%$, in Sagamu $78.3 \%$, in Ilorin $69.8 \%$ and in Benin 64\% [17-19]. All these studies make it disheartening to know that, the women who suffer this rampaging and ravaging health problem and their husbands as well as their daughters, mothers and sisters have limited knowledge on cervical cancer and its screening then, how can they make realistic decisions that would result to lower incidence, prevalence, morbidity and mortality rates of the disease. Against this background therefore the need to assess the knowledge of the population (both men and women alike) in Makurdi metropolis on cervical cancer and Pap smear screening becomes imperative.

\subsection{Objectives}

The general objective of the study is to assess the knowledge of cervical cancer and Pap smear screening of the people in Makurdi metropolis.

The specific objectives of the study were to:

(1) Examine the knowledge of cervical cancer and Pap smear screening among the older ( $\geq 30$ years) and younger $(\leq 29$ years $)$ participants in Makurdi metropolis.

(2) Examine the knowledge of cervical cancer and Pap smear screening of the single and married participants in Makurdi metropolis.

(3) Examine the knowledge of cervical cancer and Pap smear screening of participants with low and high levels of education in Makurdi metropolis.

(4) Examine the knowledge of cervical cancer and
Pap smear screening of males and females in Makurdi metropolis.

(5) Examine the knowledge of cervical cancer and Pap smear screening of health workers and non-health workers.

\subsection{Research Hypotheses}

The following hypotheses were stated and tested in the study:

(1) Older participants ( $\geq 30$ years) will significantly have better knowledge of cervical cancer and Pap smear screening than younger participants $(\leq 29$ years).

(2) Married participants will significantly have better knowledge of cervical cancer and Pap smear screening than single participants.

(3) Participants with higher educational level will significantly have better knowledge of cervical cancer and Pap smear screening than those with low educational level.

(4) Females will significantly have better knowledge of cervical cancer and Pap smear screening than males.

(5) Health workers will significantly have better knowledge of cervical cancer and Pap smear screening than non health workers.

\section{Methods}

\subsection{Design}

The study employed the exploratory survey design method, where the knowledge of cervical cancer and Pap smear screening of participants in Makurdi metropolis was assessed.

\subsection{Participants}

Five hundred and seventy-four (574) participants aged 18 to 60 years with a mean age of 30.81 , who were accidentally/conveniently sampled in Makurdi metropolis participated in the study. The participants were made up of 277 (48.3\%) males and 297 (51.7\%) females. Their other characteristics as presented in 
Table 1 indicated that $558(97.2 \%)$ were Christians and 16 (2.8\%) Muslims, 344 (59.9\%) were single, 220 $(38.3 \%)$ married and $5(0.9 \%)$ widows/widowers. Majority of them, 275 (48.9\%) were civil servants followed by students 140 (24.9\%), health workers 52 (9.1\%), business people 33 (5.9\%), applicants 28 (5\%), security personnel $10(2 \%)$ and others who did not specify their occupations 4 (4.3\%). Most of the participants, 344 (60.8\%) possessed Higher National Diploma (HND)/1st degree qualifications, $114(19.9 \%)$ OND/NCE, 62 (11\%) senior secondary school certificate (SSCE), 38 (6.6\%), masters degree, while $3(0.5 \%)$, possessed first school leaving certificate (FSLC), 2 (4\%) Ph.D. and $3(0.5 \%)$ no formal education.

\subsection{Instrument}

The instrument used to collect data for this study, was a questionnaire known as the knowledge of cervical cancer and Pap smear screening scale (KCPS) put together by the researchers which comprised of two sections. Section A consisted of items that sought information of participant's demographic variables, while section B consisted of eleven (11) items that assessed knowledge of cervical cancer and Pap smear screening of participants. Six (6) of the items assessed knowledge of cervical cancer, four (4) knowledge of Pap smear screening and one (1) sources of information of the variables. The response format was three and four point response formats for the ten items and unstructured response for item eleven (11). The scale yielded a Cronbach's alpha coefficient of 0.66.

\subsection{Procedure}

The participants where conveniently/accidentally sampled from eight areas of the town (High-Level,

Table 1 Demographic variables of participants.

\begin{tabular}{|c|c|c|}
\hline Variables & Frequency & $\%$ \\
\hline \multicolumn{3}{|l|}{ Gender } \\
\hline Males & 277 & $48.3 \%$ \\
\hline Female & 297 & $51.7 \%$ \\
\hline \multicolumn{3}{|l|}{ Religion } \\
\hline Christian & 558 & $97.2 \%$ \\
\hline Muslim & 16 & $2.8 \%$ \\
\hline \multicolumn{3}{|l|}{ Marital S. } \\
\hline Single & 344 & $59.9 \%$ \\
\hline Married & 220 & $38.3 \%$ \\
\hline Widow/widower & $5 / 5$ & $0.9 \% / 0.9 \%$ \\
\hline \multicolumn{3}{|l|}{ Occupation } \\
\hline Civil Servant & 275 & $48.9 \%$ \\
\hline Health workers & 52 & $9.1 \%$ \\
\hline Business & 33 & $5.9 \%$ \\
\hline Applicant & 28 & $5.0 \%$ \\
\hline Students & 140 & $24.9 \%$ \\
\hline Security Personnel & 10 & $1.8 \%$ \\
\hline Others & 24 & $4.3 \%$ \\
\hline \multicolumn{3}{|l|}{ Edu. Sta. } \\
\hline FSLC & 3 & $0.5 \%$ \\
\hline SSCE & 62 & $11.0 \%$ \\
\hline $\mathrm{OND} / \mathrm{NCE}$ & 114 & $19.9 \%$ \\
\hline HND/Degree & 344 & $60.8 \%$ \\
\hline Masters & 38 & $6.6 \%$ \\
\hline Ph.D & 2 & $0.4 \%$ \\
\hline Others & 2 & $0.4 \%$ \\
\hline None & 1 & $0.2 \%$ \\
\hline
\end{tabular}


North Bank, Wurukum, Wadata, Achusa, Kanshio, Brewery/Gaadi and the State Government Secretariat). The participants were approached and their consents sought, those who consented to participate were assured of confidentiality of their responses, briefed of the objective of the study and questionnaires given to them to respond to/fill out.

\subsection{Data Analysis}

Data collected were analyzed using descriptive (frequencies, percentages, means, standard deviations) and inferential statistics (independent $t$-test) using the Statistical Package for Social Sciences (SPSS version 18.0) computer software for windows was used to execute the data analysis.

\section{Results}

Participants generally displayed limited knowledge of cervical cancer and Pap smear screening with 203 (35.3\%) having knowledge, while 371 (64.7\%) indicated limited knowledge. No statistical significant difference was found in the knowledge of cervical cancer and Pap smear screening (Table 3 ) between older $(\mathrm{m} \geq 33$ years $)$ and younger $(\mathrm{m} \leq 32$ years $) t(553)=-1.69 ; P>$ 0.05 , single and married participants $t(562)=-0.97 ; P>$ 0.05 , low and high levels of education $t(564)=-1.83$; $P>0.05$.

Surprisingly, males $($ mean $=33.55 ; \mathrm{SD}=7.94)$ significantly had better knowledge than females (mean $=32.26$; $\mathrm{SD}=7.18) t(572)=2.03 ; P<0.05$; and "other" participants (mean $=33.12 ; \mathrm{SD}=7.78)$ had better knowledge than health workers (mean $=30.46$; $\mathrm{SD}=4.40) t(572)=-2.43 ; \mathrm{P}<0.05$. The participants obtained knowledge about Cervical cancer and Pap smear screening through enlightenment campaigns 138 (24\%), magazines and news papers 94 (16\%),

Table 2 Sources of participants knowledge of cervical cancer and Pap smear screening.

\begin{tabular}{lll}
\hline Source & Frequency & $\%$ \\
\hline Enlightenment Campaign & 138 & $24 \%$ \\
Magazines/Newspapers & 94 & $17 \%$ \\
Other unspecified sources & 82 & $14.4 \%$ \\
Television & 80 & $14 \%$ \\
Radio & 73 & $13 \%$ \\
Taught in school & 53 & $9 \%$ \\
Friends & 50 & $8 \%$ \\
\hline
\end{tabular}

Table 3 Independent $t$-test showing difference in the knowledge of cervical cancer and Pap smear screening on major variables.

\begin{tabular}{|c|c|c|c|c|c|c|c|}
\hline variables & $\mathrm{N}$ & $\overline{\mathrm{X}}$ & SD & SE & $\mathrm{df}$ & $t$ & $P$ \\
\hline Age & & & & & 553 & -1.69 & 0.092 \\
\hline Older & 432 & 33.06 & 7.43 & 0.36 & & & \\
\hline Younger & 123 & 31.76 & 7.95 & 0.72 & & & \\
\hline Marital S. & & & & & 562 & -0.97 & 0.33 \\
\hline Single & 344 & 32.61 & 7.59 & 0.41 & & & \\
\hline Married & 220 & 33.24 & 7.52 & 0.51 & & & \\
\hline Level of edu. & & & & & 564 & -1.83 & 0.068 \\
\hline Low & 524 & 32.53 & 7.50 & 0.84 & & & \\
\hline High & 42 & 34.69 & 5.46 & 0.84 & & & \\
\hline Gender & & & & & 572 & 2.03 & $\leq 0.05$ \\
\hline Males & 277 & 33.55 & 7.94 & 0.48 & & & \\
\hline Females & 297 & 32.26 & 7.18 & 0.42 & & & \\
\hline Occupation & & & & & 572 & -2.43 & $\leq 0.05$ \\
\hline Health workers & 52 & 30.46 & 4.40 & 0.61 & & & \\
\hline Others & 522 & 33.12 & 7.78 & 0.34 & & & \\
\hline
\end{tabular}


Television 80 (14\%), radio 73 (13\%), school 53 (9\%), friends $50(8.7 \%)$ and other unspecified ways 82 $(14.3 \%)$ as in table 2 .

\section{Discussion and Conclusions}

The findings show that there is generally limited knowledge of cervical cancer and Pap smear screening in Makurdi metropolis. This finding supports the works by Apampa, Nakalevu, Hyacinth, Adekeye, Ibeh and Osoba, Igwilo, et al. and Abiodun, et al. [8, 9, $11,20,21]$ that reported limited to poor knowledge and awareness of cervical cancer and pap smear screening amongst their populations in Nigeria.

The result of the hypothesis which states that older participants will significantly have better knowledge of cervical cancer than younger participants was not confirmed. This implies that the knowledge of cervical cancer and Pap smear screening of older participants with (mean $=33.06)$ and younger participants with $($ mean $=31.76)$ was not dependent on their age. The fact that the older participants have a slightly higher mean has not affected their knowledge of the variables of study over the younger participants.

Findings of this study on marital status, and levels of education did not yield any statistical significant difference, which implies that the limited knowledge shown by the participants is not dependent on these variables. The findings with regards to gender imply that males had better knowledge than females, which is rather surprising because cervical cancer and Pap smear screening is an issue that concerns females and they should naturally know better. Though no known earlier study in this area has included males, this study decided to include them in the sample population because men have an important role to play in the lives of women, by encouraging them and providing financial assistance to their wives, mothers, sisters, daughters and friends to seek and utilize Pap smear screening tests. Better knowledge of the male participants could be attributable to the sources of information on the knowledge of the issue, which were mainly from the mass media such as newspapers, magazines, television and radio. Males tend to have more interest in utilizing these media sources of information than the female in Nigeria.

The result of the hypothesis which states that health workers will significantly have better knowledge of cervical cancer and Pap smear screening than non health workers was statistically significant, but the hypothesis was not confirmed in the direction of the hypothesis since it was non-health workers that had better knowledge of the problem than the health workers. This implies that other participants had better knowledge than health workers. This finding does not support earlier studies carried out among female health workers in Ilorin with $69.8 \%$ of health workers having knowledge and awareness [15], Nnewi which recorded $87 \%$ of knowledge and awareness [19]. Awodele, Adeyomoye, Awodele, Kwashi, Awodele and Dolapo [22], reported high (99\%) knowledge and awareness in Lagos; and over 65\% awareness among healthcare workers in Benin [18]. This study was not targeted at health workers per se, therefore their population in this study was small $(\mathrm{n}=52)$ which may have influenced this finding.

Enlightenment campaigns (24\%) were the major single source that the participants acquired their knowledge in this study. However, in combination, the combined media sources of magazines, newspapers, television and radio constitute the major sources (44\%) participants acquired knowledge on the issue. This finding therefore supports the works of Awodele et al. [22] who in Lagos obtained information majorly through the electronic media, and Oche, Kaoje, Gana and Ango [23], obtained information through lectures and seminars (76\%) while in school and the work place.

The study concluded that, there is limited knowledge of cervical cancer and Pap smear screening in Makurdi metropolis and hence the need to intensify the sensitization of the people through both media and enlightenment campaigns to reduce morbidity and mortality. 


\section{Reference}

[1] World Health Organisation 2014. Comprehensive Cervical Cancer Control. A Guide to Essential Practice 2nd Edition. WHO Press, World Health Organization, 20 Avenue Appia, 1211 Geneva 27, Switzerland. ISBN. 9789241548953.

[2] Adewole, I. I., and Ogundipe, S. 2013. Cervical Cancer Crises: Nigeria, 4 Others in the Eye of the Storm. Vanguard Mobile Edition; May, 14th www.vanguardngr.com/2013/05/ cervical cancer crises.

[3] Ogundipe, S. 2013. Cervical Cancer Crises: Nigeria, 4 Others in the Eye of the Storm. Vanguard Mobile Edition; 9-75, May, 14th www.vanguardngr.com/2013/05/ cervical cancer crises.

[4] Koutsky, L. A. 1997. "Epidemiology of Genital Human Papillomavirus Infection." American Journal of Medicine 102 (5A): 3-8.

[5] Crum, C. P., Abbott, D. W., and Quade, B. J. 2003. "Cervical Cancer Screening" and Denise A. Galloway, "Papillomavirus Vaccines in Clinical Trials." Lancet Infectious Diseases 3 (8): 46.

[6] Campbell, O. 2011. An Over View of Cancer Burden in Nigeria. A presentation made at the one week Psycho Oncology training workshop held at the University College Hospital Ibadan, from 3rd-6th October, 2011.

[7] Cracchiolo, B., and Leitao, M. Jr. 2006. Update on Cervical Cancer. Health Link.

[8] Apampa, R. A. 2009. Comparative Study of Knowledge of Cervical Cancer and Screening Practice among Female Staff of University of Lagos, Akoko and Yaba College of Technology, Yaba Lagos. Unpublished Masters of Public Health Dissertation.

[9] Abiodun, O. A., Fatungase, O. K., Olu-Abiodun, O. O., Idowu-Ajiboye, B. A., and Awosile, J. O. 2013. "An Assessment of Women's Awareness and Knowledge about Cervical Cancer and Screening and the Barriers to Cervical Screening in Ogun State, Nigeria." IOSR Journal of Dental and Medical Sciences 10 (3): 52-8.

[10] Nwankwo, K. C., Aniebue, U. U., Aguwa, E. N., Anarado, A. N., and Agunwah, E. 2011. "Knowledge Attitudes and Practices of Cervical Cancer Screening among Urban and Rural Nigerian Women: A Call for Education and Mass Screening." European Journal of Cancer Care 20 (3): 362-7.

[11] Nakalevu, S. M. 2009. The Knowledge, Attitude, Practice and Behavior of Women towards Cervical Cancer and Pap Smear Screening. A Cross Sectional Study in the Rewa Subdivision. A Dissertation Submitted in Partial Fulfillment of the Requirements for Masters in Public Health, Fiji School of Medicine.

[12] Feyi-Waboso, P. A., Kamanu, C., and Aluka, C. 2005.
"Awareness and Risk Factors for Cervical Cancer among Women in Aba, South-eastern Nigeria." Tropical Journal of Obstetrics and Gynecology 22 (3): 25-6.

[13] Audu, B. M., El-Nafaty, A. U., Khalil, M., and Otubu, J. A. 1999. "Knowledge and Attitudes to Cervical Cancer Screening among Women in Maiduguri, Nigeria." Journal of Obstetric and Gyneacology 19 (3): 295-7.

[14] Ojiyi, E. O., and Dike, E. I. 2008. "Knowledge and Practice of Cervical Cancer Screening at the Imo State University Teaching Hospital, Orlu." PHMJ 2 (2): 145-51.

[15] Ayinde, O. A., Omigbidun, A. O., and Ilesanmi, A. O. 2004. "Awareness of Cervical Cancer, Papanicolaous Smear and Its Utilization among Female Undergraduates in Ibadan." African Journal of Reproductive Health 8 (3): 68-80.

[16] Ogunbode, O. O. 2005. "Awareness of Cervical Cancer and Screening in a Nigerian Female Market Population." Annals of African Medicine 9: 194-5.

[17] Aboyeyi, P. A., Iyayi, M. A., and Jimoh, A. A. 2006. "Knowledge, Attitudes and Practice of Cervical Smear as a Screening Procedure for Cervical Cancer in Ilorin, Nigeria." Tropical Journal of Obstetrics and Gyneacology 21: 114-7.

[18] Gharoro, E. P., and Ikeanyi, E. N. 2006. "An Appraisal of the Level of Awareness and Utilization of the Pap Smear as a Cervical Cancer Screening Test among Female Health Workers in a Tertiary Health Institution." International Journal of Gynecology Cancer 16: 1063-8.

[19] Udigwe, G. O. 2006. "Knowledge, Attitude and Practice of Cervical Cancer Screening (Pap smear) among Female Nurses in Nnewi, South Eastern Nigeria." Nigerian Journal of Clinical Practice 9 (1): 40-3.

[20] Hyacinth, I. H., Adekeye, O. A., Ibeh, J. O., and Osoba, T. 2012. "Cervical Cancer and Pap Smear Awareness and Utilization in North Central Nigeria." PLOS ONE 7 (10): e46583. doi: 10.1371/journal.pone.0046583.

[21] Igwilo, A. I., Igwilo, U. U., Hassan, F., Idanwekhai, M., Igbinomwanhia, O., and Popoola, A. O. 2012. "The Knowledge, Attitude and Practice of the Prevention of Cancer of the Cervix in Okada Community." Asian Journal of Medical Sciences 4 (3): 95-8. ISSN: 2040-8773. Maxwell Scientific Organization.

[22] Awodele, O., Adeyomoye, A. A. A., Awodele, D. F., Kwashi, V., Awodele, O., and Dolapo, D. C. 2011. "A Study on Cervical Cancer amongst Nurses in Lagos University Teaching Hospital, Lagos, Nigeria." Journal of Cancer Education 26 (3): 497-504.

[23] Oche, M. O., Kaoje, A. U., Gana, G., and Ango, J. T. 2013. "Cancer of the Cervix and Cervical Screening: Current Knowledge, Attitudes and Practices of Female Health Workers in Sokoto, Nigeria." International Journal of Medicine and Medical Sciences 5 (4): 184-90. 